\title{
O papel da odontologia na equipe interdisciplinar: contribuindo para a atenção integral ao idoso
}

\author{
The role of dentistry in the interdisciplinary \\ team: contributing to comprehensive health \\ care for the elderly
}

Rosemary Sadami Arai Shinkai 1,2

Altair Antoninha Del Bel Cury 1

\footnotetext{
1 Departamento de Prótese e Periodontia, Faculdade de Odontologia de Piracicaba, Universidade Estadual de Campinas. Av. Limeira 901, Piracicaba, SP 13416-740, Brasil. 2 Departamento de Administração e Planejamento em Saúde, Escola Nacional de Saúde Pública, Fundação Oswaldo Cruz. Rua Leopoldo Bulhões 1480, 70 andar, Rio de Janeiro, $R J$ 21041-210, Brasil. rosemary_shinkai@yahoo.com altcury@fop.unicamp.br
}

\begin{abstract}
This literature review focuses on dentistry's role in comprehensive health care for the elderly. The authors discuss the need for an interdisciplinary approach. They begin by analyzing the current situation in geriatric dentistry and related problems in Brazil, relating primarily to the lack of specific studies and human resources with training in geriatrics and gerontology. The authors emphasize interactions between dentistry and other health professions for health promotion, specific prevention, and rehabilitation of elderly patients, with special attention to the importance of communication and information exchange.
\end{abstract}

Key words Geriatric Dentistry; Aging Health; Aged; Aging

Resumo Este trabalho bibliográfico teve por objetivo discutir a atuação da odontologia na atenção integral à saúde do idoso, considerando-se a necessidade da abordagem interdisciplinar. É apresentada a atual situação da odontologia geriátrica e os problemas que ocorrem no Brasil pela falta de estudos específicos e de recursos humanos capacitados em geriatria e gerontologia dentro da odontologia. São destacadas as interações entre as diversas profissões de saúde e a odontologia, para a promoção de saúde, prevenção específica e reabilitação de pacientes idosos, com ênfase na importância da comunicação e troca de informações.

Palavras-chave Odontologia Geriátrica; Saúde do Idoso; Idoso; Envelhecimento 


\section{Introdução}

Um dos grandes desafios para a atenção ao idoso advém do fato de que quanto mais envelhecem, mais diferentes se tornam as pessoas. $\mathrm{O}$ agrupamento de indivíduos com histórias biológica, psíquica e social distintas em uma mesma faixa etária resulta em grande heterogeneidade de características e demandas. $\mathrm{O}$ atendimento, portanto, requer um olhar e um interagir com a compreensão da individualidade do idoso, o que inviabiliza e exclui qualquer abordagem de caráter universal.

Além da heterogeneidade biopsicossocial, outro fator complicador para a assistência à terceira idade é a situação de complexidade clínica freqüentemente encontrada com o envelhecimento: co-morbidade, mecanismos de adaptação, vulnerabilidade orgânica, apresentação atípica de doenças e maior suscetibilidade à iatrogenia.

Considerando-se a diversidade e a complexidade do idoso, a atuação de uma equipe interdisciplinar torna-se fundamental, na medida em que participa, analisa e integra conhecimentos específicos de diversas áreas com o objetivo comum de promover e manter a saúde do idoso. A assistência à terceira idade é uma área de contato de muitas especialidades; a troca de conhecimentos facilita a atuação de cada elemento do grupo dentro do conceito de "descentralização integrada" (Jacob Filho \& Sitta, 1996). Através de uma linguagem comum às áreas envolvidas, é estabelecido um intercâmbio profissional nas interfaces do saber, ou seja, na interseção dos conhecimentos de uma e outra (ou outras) áreas. Cada ator desempenha suas funções específicas dentro de um planejamento conjunto da equipe, com co-responsabilidade no processo de decisão.

Nesse contexto de atenção interdisciplinar ao idoso, a participação do cirurgião-dentista e do técnico em higiene dental ainda não é muito efetiva. A literatura sobre a odontologia na prática interdisciplinar na terceira idade é quase inexistente, havendo poucas menções de dentistas em equipes de assistência ao idoso (Saunders, 1996). Uma das razões dessa dificuldade de vivência interdisciplinar para a odontologia reside na formação de base tecnicista, que privilegia o enfoque de superespecialização (Ferreira, 1997). É uma visão limitada de postura odontológica intervencionista, que tem suas raízes históricas fincadas em conceitos ultrapassados de saúde bucal desvinculada da saúde geral, sendo totalmente inadequada para o atendimento ao idoso.

Essa situação ocorre não por ausência de demandas odontológicas na terceira idade. Es- tudos sobre o impacto das condições bucais na qualidade de vida e no bem-estar do indivíduo idoso revelam que os aspectos funcionais, sociais e psicológicos são significativamente afetados por uma condição bucal insatisfatória (Locker \& Slade, 1993; Strauss \& Hunt, 1993). Tal fato se torna mais crítico quando se considera que muitos idosos não têm acesso ao tratamento odontológico necessário ou adequado.

Outro aspecto a ser considerado é a mudança gradual que vem ocorrendo no perfil bucal do idoso. Apesar dos altos índices de edentulismo ainda presentes, principalmente nos países menos desenvolvidos como o Brasil, em grande parte do mundo há tendência de maior retenção dos dentes naturais pela população que está envelhecendo (Künzel, 1991; Rutkauskas, 1997), o que aumenta a complexidade de cuidados pessoais e de atenção profissional com a pluralidade de quadros clínicos.

Deve ser discutida ainda a necessidade de eliminação dos preconceitos em relação à atuação da odontologia. Assim como o idoso não deve ser uma boca para o dentista, e boca em idoso não se restringe à dentadura, a odontologia não se limita à boca, e esta não é igual a dentes e gengiva. É preciso que haja afastamento de mitos e estereótipos que cercam o tratamento odontológico na terceira idade, bem como divulgação de informações entre os próprios cirurgiões-dentistas, os demais profissionais de saúde, as autoridades e a população em geral, incluindo principalmente os idosos e seus familiares.

Assim sendo, este trabalho de orientação bibliográfica tem por objetivo discutir o papel da odontologia na atenção ao idoso, na perspectiva de interdisciplinaridade. São abordadas as ações odontológicas na promoção de saúde, prevenção de morbidades e reabilitação, como parte integrante de um plano comum para o bem-estar dos idosos nas suas dimensões biológica, psicológica e social.

Esse viés se dá em virtude do posicionamento ainda não muito claro da odontologia perante as demais áreas profissionais envolvidas na atenção ao idoso; assim, o desconhecimento da amplitude da atuação odontológica gera dúvidas. A odontologia é realmente importante na equipe? Em que situações ela pode contribuir para alcançar os benefícios máximos para o indivíduo idoso? Por outro lado, a odontologia também precisa obter da geriatria e da gerontologia as bases para uma prática de atendimento, seja preventiva ou curativa, com uma visão geral do idoso e do envelhecer. Então, não se trata somente de como a odontologia pode ajudar a equipe, mas também de co- 
mo ela pode ser ajudada, como o conhecimento das outras áreas vai se tornar essencial para a atuação odontológica na terceira idade.

\section{A odontologia e o idoso}

A 2a Conferência Nacional de Saúde Bucal (2a CNSB), realizada em setembro de 1993 como deliberação da 9ạ Conferência Nacional de Saúde, reafirmou a condição indissociável da saúde bucal com o todo do ser humano: "A saúde bucal é parte integrante e inseparável da saúde geral do indivíduo e está relacionada diretamente com as condições de saneamento, alimentação, moradia, trabalho, educação, renda, transporte, lazer, liberdade, acesso e posse da terra, aos serviços de saúde e a informação" (CFO, 1993:1).

Esse conceito de saúde bucal indica o caráter abrangente da atenção odontológica e a necessidade de sua integração a todos os aspectos da vida do indivíduo. Logo, também está plenamente de acordo com a visão holística de saúde no idoso. Apesar de não conter nenhuma menção explícita à terceira idade, o capítulo Modelo de Atenção em Saúde Bucal, do relatório final da 2 a CNSB, salienta a garantia à "assistência integral em todos os níveis e faixas etárias”, e propõe ainda "garantir que os portadores de deficiência física, mental, motora ou múltiplas, ou de doenças infecto-contagiosas e crônico-degenerativas tenham o seu atendimento básico executado em qualquer Unidade Básica de Saúde da rede SUS que deverá contar com concepção arquitetônica adequada, normas e rotinas de biossegurança, e recursos humanos devidamente capacitados para tal fim" (CFO, 1993:16).

Entretanto, a realidade ainda não contempla essas diretrizes de atenção à saúde bucal, principalmente para determinados grupos populacionais, como os idosos e os chamados pacientes especiais. São várias as causas para essa situação no atendimento odontológico à população, envolvendo aspectos históricos, geográficos, financeiros e políticos, como apontado no relatório da 2a CNSB.

Um desses problemas refere-se ao desconhecimento das reais condições bucais da população brasileira. Com exceção do grupo de crianças em idade escolar, em área urbana, não são realizados levantamentos sobre saúde bucal de forma mais sistemática. Além disso, nos levantamentos realizados, os dados em geral são restritos a prevalência e incidência de cárie dental, desconsiderando-se as outras afecções bucais.

Especificamente no caso do atendimento odontológico ao idoso no Brasil, não há, até o momento, estudos epidemiológicos amplos sobre as condições de saúde bucal na terceira idade, o que impossibilita o estabelecimento de prioridades e o desenvolvimento de ações coerentes de assistência, principalmente em nível coletivo. Segundo Narvai (1999), em 1986, o Ministério da Saúde realizou o primeiro estudo em escala nacional para se conhecer a situação de saúde bucal da população: o Levantamento Epidemiológico Nacional em Saúde Bucal: Brasil, Zona Urbana, 1986. Foram coletados dados em 16 capitais brasileiras, consideradas representativas das cinco macrorregiões do Brasil adotadas pelo IBGE (Fundação Instituto Brasileiro de Geografia e Estatística), no entanto a faixa etária mais avançada avaliada nessa pesquisa foi a de 50 a 59 anos de idade. Alguns poucos estudos isolados e mais delimitados sobre a saúde bucal em pessoas de sessenta anos ou mais têm sido feitos por acadêmicos, como Rosa et al. (1992) e Pucca Jr. (1998).

A esse quadro de desconhecimento epidemiológico, soma-se a falta de recursos humanos capacitados para o atendimento odontológico de idosos. O estudo mais profundo dos aspectos geriátricos e gerontológicos em odontologia pode ser considerado recente, embora algumas disciplinas tenham-se dedicado a problemas prevalentes na terceira idade, como o edentulismo e a doença periodontal. Entretanto, na maioria das vezes, a abordagem a tais aspectos era realizada sem o enfoque específico do processo de envelhecimento e de suas conseqüências.

A introdução da geriatria e da gerontologia na área odontológica vem sendo feita de forma lenta e não sistematizada no Brasil e na maioria dos países em desenvolvimento que estão passando pela transição demográfica. Mesmo nos países do Primeiro Mundo, a odontologia geriátrica consolidou seu espaço apenas no final dos anos 70 e na década seguinte. São exemplos a fundação da International Association of Gerodontology (IAG), em 1983 (Künzel, 1991); a primeira reunião do grupo de trabalho da Federação Dentária Internacional, sobre a saúde bucal do idoso, em 1988 (FDI, 1993); o desenvolvimento de programas e módulos curriculares em Odontologia Geriátrica para as faculdades de Odontologia dos Estados Unidos, nos anos 80 (Werner et al., 1998).

No Brasil, em 1982, Albuquerque (1982) já sugeria a inclusão da Odontologia Geriátrica no currículo odontológico. Essa demanda curricular também foi defendida por Madeira et al. (1987), em vista do aumento da população idosa e da necessidade desta de cuidados odontológicos especializados, com amplo conheci- 
mento de gerontologia e das alterações provocadas pelo envelhecimento. Na prática, uma iniciativa bem-sucedida de incorporação da Odontogeriatria na grade curricular de graduação é a experiência da Universidade Estadual de Maringá, no Paraná (Kina et al., 1997).

Apesar de ser uma medida importante, a inclusão formal da Geriatria e da Gerontologia nos currículos das faculdades de odontologia não é suficiente. Em face do rápido processo de envelhecimento populacional no Brasil e do acúmulo de problemas de saúde bucal durante a vida dos indivíduos, há necessidade urgente de formação e capacitação de recursos humanos em odontologia geriátrica não apenas de cirurgiões-dentistas, mas também de toda uma equipe de saúde bucal que possa viabilizar o atendimento à população idosa em larga escala. Assim, a participação de pessoal auxiliar de nível elementar e médio, como técnicos em higiene dental e atendentes de consultório dentário, deve ser incentivada e requerida, possibilitando otimização do trabalho e maior cobertura de assistência aos idosos, em nível público e privado.

\section{A ação específica da odontologia geriátrica}

Segundo Holm-Pedersen \& Löe (1996), odontologia geriátrica é o termo freqüentemente aceito para a disciplina da Odontologia que cuida da saúde bucal da população idosa, em especial dos pacientes que se apresentam debilitados. O termo gerontologia oral é igualmente adotado para refletir o caráter de interdisciplinaridade e enfatizar a abordagem clínica necessária para a assistência odontológica à terceira idade. Outras denominações propostas são: gerodontologia, geriodontologia, gerodontoestomatologia, geriodontoestomatologia, gerontoestomatologia, estomatogerontologia, estomatogeriatria e geroestomatologia (Künzel, 1991). Na América Latina, uma terminologia que vem sendo difundida é odontogeriatria (Jitomirski \& Jitomirski, 1987; Madeira et al., 1987; Roisinblit, 1996; Ferreira, 1997).

Sob o ponto de vista anátomo-funcional, a área de atuação específica da odontologia é o sistema estomatognático, o qual compreende dentes, tecidos periodontais, mucosa bucal, língua, glândulas salivares, maxila e mandíbula, musculatura mastigatória e articulação têmporo-mandibular. Várias alterações anatômicas e fisiológicas ocorrem nessas estruturas com o envelhecimento e a senescência, mas não necessariamente constituem desequilíbrios no pro- cesso saúde-doença. Muitos problemas odontológicos encontrados no idoso são, na realidade, complicações de processos patológicos acumulados durante toda a vida do indivíduo, devido à higiene bucal deficiente, iatrogenia, falta de orientação e de interesse em saúde bucal e ao não-acesso aos serviços de assistência odontológica (Dini \& Castellanos, 1993; Pucca Jr., 1996). Todavia, certas condições decorrentes do envelhecimento predispõem ao desenvolvimento de algumas morbidades no sistema estomatognático, como, por exemplo, o câncer bucal, que apresenta a variável idade como fator de risco (INCA, 1996/1999; Salisbury, 1997).

Na literatura odontológica especializada (Holm-Pedersen \& Löe, 1996; Pucca Jr., 1996; Rutkauskas, 1997), relatam-se os seguintes problemas de saúde bucal mais prevalentes no idoso: cárie coronária e radicular, periodontopatias, edentulismo, desgastes dentais (atrições, abrasões e erosões), lesões de tecidos moles (ulcerações, hiperplasias inflamatórias traumáticas e medicamentosas, infecções etc.), xerostomia, dores orofaciais, desordens têmporo-mandibulares, problemas de oclusão e câncer bucal (não estão citados em ordem de prevalência ou de relevância clínica).

A análise dos problemas odontológicos freqüentemente encontrados nos idosos é derivada de levantamentos epidemiológicos internacionais, desenvolvidos principalmente nos Estados Unidos e nos países escandinavos (HolmPedersen \& Löe, 1996; Rutkauskas, 1997). Como citado anteriormente, a casuística brasileira sobre a saúde bucal do idoso é pobre. Alguns trabalhos epidemiológicos brasileiros realizados em idosos observaram um nível bastante precário de saúde bucal nas populações estudadas.

Rosa et al. (1992) realizaram um levantamento sobre as condições bucais em 236 pessoas de sessenta anos ou mais, no Município de São Paulo. Foram avaliados idosos institucionalizados e não institucionalizados de diferentes níveis sócio-econômicos. Observaram-se altos índices de cáries, com CPO (cariados, perdidos e obturados) 29,03, para os idosos examinados no domicílio e CPO 30,97, para os institucionalizados. Em relação ao edentulismo, $65 \%$ dos idosos não institucionalizados eram edêntulos, e, destes, $76 \%$ usavam próteses totais superior e inferior. Nos idosos internados, $84 \%$ eram edêntulos e apenas $30 \%$ destes usavam próteses bimaxilares. Nos usuários de próteses, lesões relacionadas das mucosas estavam presentes em $38 \%$ e $53 \%$ dos idosos não institucionalizados e institucionalizados, respectivamente, indicando falta de assistência 
odontológica após a colocação das próteses. Quanto às doenças periodontais, bolsas periodontais foram encontradas em metade dos idosos examinados no domicílio e em dois terços examinados nas instituições.

Também no Município de São Paulo, Pucca Jr. (1998) avaliou a prevalência de edentulismo e o uso de prótese dentária em um estudo longitudinal de dois anos (de 1992 a 1994) com idosos de 65 anos e mais. Os dados da saúde bucal, colhidos através de entrevistas, revelaram uma prevalência auto-referida de edentulismo de $54,8 \%$ no primeiro inquérito ( 1.667 idosos) e de $56 \%$ no segundo inquérito ( 1.108 idosos). O uso de prótese dentária foi de $86,3 \%$ e de $84,8 \%$ nos primeiro e segundo inquéritos, respectivamente.

Um outro levantamento transversal das condições de saúde bucal de adultos acima de 55 anos foi realizado em Pelotas, Rio Grande do Sul, em 1995, com pessoas não institucionalizadas, moradoras de um bairro da periferia (Frare et al., 1997). Observou-se uma prevalência de $64,6 \%$ de edentados totais, dos quais $73,4 \%$ usavam próteses dentárias. Nos entrevistados dentados, $34 \%$ apresentavam alterações gengivais de forma e cor, e a maioria relatou escovar os dentes ao menos uma vez ao dia. Outros achados relevantes foram periodontite severa, candidíase, provocada pelo uso de dentadura e por falta de higiene bucal, e hiperplasia no palato em razão da prótese total com câmara de sucção.

Todos esses estudos delineiam um quadro de alta prevalência de edentulismo, cáries dentárias e periodontopatias, refletindo o fracasso ou a inexistência da assistência odontológica para a população idosa analisada (Pucca Jr., 1996). Além disso, como observado por Rosa et al. (1992), a prevenção em odontologia só passou a despertar interesse no Brasil no final da década de 70, o que poderia explicar, em parte, os baixos níveis de saúde bucal no idoso. Por esse raciocínio, os efeitos das medidas odontológicas preventivas só serão mais evidentes em gerações futuras de idosos brasileiros.

Embora a atuação odontológica deva ocorrer em todos os níveis - promoção de saúde, prevenção específica e reabilitação, por meio de medidas integradas entre si e no contexto biopsicossocial do indivíduo -, a prevenção primária é destacada como estratégia fundamental para a saúde bucal dos idosos. A Federação Dentária Internacional (FDI) recomenda, para os países em desenvolvimento, a aplicação de serviços preventivos extensos para comunidades e a distribuição de recursos, quando escassos, para a prevenção e a educação em lugar dos procedimentos restauradores (FDI, 1993).
Esse aspecto é reforçado por Rosa et al. (1992), que salientam a necessidade de políticas nacionais, estaduais e municipais de saúde com ênfase na prevenção em idosos para reduzir os níveis de doença, a fim de que "as necessidades de tratamento não sufoquem a capacidade de atendimento" (Rosa et al., 1992:159).

Entretanto, o sucesso de programas de prevenção não depende apenas de ações governamentais específicas. Nos Estados Unidos, estudos nacionais realizados durante os últimos trinta anos forneceram dados que indicam diminuição progressiva de edentulismo em adultos (de 35 a 74 anos de idade), provavelmente associada à alteração de valores e atitudes em relação à saúde bucal (Ettinger, 1997). Essas alterações teriam sido influenciadas pelo avanço tecnológico da odontologia (materiais restauradores, anestesia, alta-rotação), a fluoretação da água de abastecimento público e a prosperidade da sociedade, possibilitando acesso aos serviços odontológicos e a utilização destes. Além disso, também os dentistas mudaram suas atitudes, passando da postura radical fundada no binômio extração/dentadura para uma intervenção com bases preventiva e restauradora.

Dessa forma, a melhora nas condições de saúde bucal está essencialmente ligada aos valores a esta atribuídos pela população. No entanto, no estudo de Strauss \& Hunt (1993) com idosos americanos sobre o impacto das condições bucais na vida diária, houve uma alta porcentagem de respostas "sem efeito" (nem positivo e nem negativo) para os aspectos funcionais, sociais e psicológicos associados a dentes e próteses, o que indica uma baixa autopercepção desses valores.

A incorporação de hábitos e de modos de vida mais saudáveis requer uma postura ativa e consciente da população. Para isso, é necessário que ela saiba para querer, e queira para pedir e fazer. A informação e a orientação básica da população constituem os meios mais efetivos para modificar a autopercepção em relação aos aspectos de saúde, incluindo-se a saúde bucal. Trata-se de retirar da população da terceira idade o estigma de naturalmente doente, idéia que o próprio indivíduo idoso tem de si, para que as necessidades de saúde sejam percebidas e se tornem reais. Somente a partir daí ocorrem mudanças de atitudes pessoais, que são pré-requisitos para a reivindicação de medidas específicas e sua aceitação. Particularmente em relação à saúde bucal em idosos, esse aspecto é fundamental para que os indivíduos e seus familiares e/ou cuidadores mantenham a motivação para o autocuidado e o seguimento de prescrições profissionais. 
Paralelamente, há necessidade de organização das comunidades e de uma rede de assistência profissional preparadas para atender a população dentro do paradigma de promoção de saúde. Uma vez que a autopercepção de saúde bucal pode ser diferente no idoso e no adulto jovem, o que implica diferentes abordagens profissionais, deve-se salientar a importância de se entenderem os valores e as percepções de saúde bucal do idoso, também a fim de melhorar as estratégias de ação de educadores e profissionais de saúde (Strauss \& Hunt, 1993). Sem essa compreensão dos reais anseios do paciente não haverá sucesso, quaisquer que sejam os planos de atendimento, tanto em nível coletivo, quanto individual.

A informação e a orientação são também peças-chave nas ações odontológicas de prevenção específica e devem ser extensivas a todos na equipe interdisciplinar. A prática interdisciplinar é fundamental na odontologia geriátrica preventiva, pois o contato com os profissionais da área odontológica pode ocorrer tardiamente. Assim, os idosos e seus familiares, médicos, enfermeiras, cuidadores e toda a equipe devem estar cientes dos potenciais problemas odontológicos no idoso e da importância da higiene bucal diária, principalmente à medida que as condições debilitantes sistêmicas se agravam (Iacopino, 1997; Reynolds, 1997). A manutenção precária da saúde bucal nesses pacientes pode levar a graves complicações de ordem local (cáries extensas, periodontopatias progressivas, lesões de mucosas e infecções oportunistas) e de ordem sistêmica.

Assim, diagnosticados os potenciais problemas e riscos do paciente idoso, a equipe odontológica pode tomar medidas preventivas específicas para cada caso, como reorientação de higiene bucal, limpeza profissional, fluorterapia e uso de agentes químicos antimicrobianos. Medidas preventivas mais agressivas e controle mais rígido são, então, instituídos para pacientes com avaliação de alto risco por fatores locais (diminuição do fluxo salivar), fatores sistêmicos (doenças incapacitantes) ou deficiências cognitivas.

O controle do ambiente bucal é a medida preventiva específica mais importante em idosos, principalmente para a prevenção de cáries dentais, sejam coronárias ou radiculares, periodontopatias e infecções oportunistas, principalmente por Candida albicans. A remoção mecânica da placa bacteriana através de escova e fio dental constitui um procedimento básico de higiene pessoal que não deve ser negligenciado, tanto para pacientes dentados, como para os pacientes portadores de próteses. A ausência e/ou deficiência de atos mecânicos possibilita o acúmulo de uma placa bacteriana cada vez mais espessa, criando condições para o desequilíbrio da microbiota residente bucal, que leva à destruição de tecidos duros e moles (Cury, 1999).

O uso de diversas substâncias antimicrobianas para o controle químico da placa bacteriana bucal tem sido amplamente pesquisado. Uma de suas indicações clínicas seria para pacientes especiais, com dificuldades para o controle mecânico da placa, em especial quando há dependência dos cuidados de outra pessoa (Cury, 1999). Em pacientes idosos com alto risco para cáries e gengivites, a utilização de clorexidina a $0,12 \%$ tem se mostrado eficaz para controlar a população bacteriana bucal (Erickson, 1997; Niessen \& Gibson, 1997). O uso associado de fluoretos e clorexidina, nas suas diversas apresentações (solução para bochechos, dentifrício, verniz ou gel, com diferentes concentrações) e posologias, é indicado para pacientes idosos de alto risco (Erickson, 1997; Niessen \& Gibson, 1997; Salisbury, 1997). Em um estudo in situ, Del Bel Cury et al. (1994) verificaram que bochechos diários duas vezes/dia com uma formulação experimental de fluoreto de sódio a $0,05 \%$ e clorexidina a $0,12 \%$ reduziu significativamente a formação de placa bacteriana dental, sem interferir com a ação do flúor. Apesar de sua eficiência no controle químico da placa, as substâncias antimicrobianas não devem ser utilizadas como substitutas do controle mecânico, mas sim como coadjuvantes do programa preventivo ou terapêutico (Cury, 1999).

Outro problema de saúde bucal importante em idosos é o câncer de boca, principalmente o carcinoma epidermóide. A incidência do câncer de boca aumenta após os quarenta anos e tem implicações graves, como causa direta de mortalidade, de amplas mutilações pós-cirúrgicas e de complicações bucais severas pós-radioterapia (por lesão de glândulas salivares, lesões vasculares e ósseas). O diagnóstico e o tratamento precoces proporcionam cura em cerca de $80 \%$ dos casos, entretanto $60 \%$ destes chegam aos centros de referência brasileiros nos estádios III e IV, quando o tratamento não é mais curativo (INCA, 1996/1999). Assim, a orientação dos fatores de risco (tabagismo, alcoolismo, irritação mecânica das mucosas bucais) e o diagnóstico precoce do câncer de boca são medidas preventivas que requerem o envolvimento de todos os profissionais que cuidam do idoso, e não só do cirurgião-dentista.

Embora a odontologia preventiva seja prioritária nos idosos, a reabilitação bucal, através de restaurações diretas e todos os tipos de pró- 
teses, representa um papel muito importante nesse segmento da população. Devido ao acúmulo de problemas odontológicos durante toda a vida do idoso, a odontologia restauradora vem auxiliar no restabelecimento da função (mastigação, fonação e deglutição) e da estética dos dentes, as quais influenciam o bem-estar do indivíduo direta e indiretamente. Assim, a intervenção odontológica em nível curativo tem implicações na alimentação, na auto-imagem, na auto-estima e no convívio social (Locker \& Slade, 1993; Strauss \& Hunt, 1993; Wolf, 1998). Contudo, infelizmente, alguns obstáculos restringem a cobertura das demandas, como o custo bem mais elevado dos procedimentos restauradores em relação à odontologia preventiva. Esse custo está associado ao grau de complexidade clínica e à inexistência, na prática, de assistência odontológica reabilitadora para adultos em nível público.

\section{A interação com outras áreas profissionais}

Uma vez que a saúde bucal é indissociável da saúde como um todo, fatores gerais do indivíduo e do ambiente afetam o sistema estomatognático e vice-versa, o que torna o conhecimento dessas interações de extrema importância para o diagnóstico das reais necessidades e prioridades do idoso, bem como para o delineamento do plano de ação. Assim sendo, o trabalho com a terceira idade exige a formação de uma ampla rede de conhecimentos de mão dupla.

Por um lado, é necessário que dentistas e pesquisadores considerem o impacto da saúde geral e das condições de vida sobre a saúde bucal. Essa informação é particularmente importante, por exemplo, no atendimento a pacientes com deficiências cognitivas, comprometimento sistêmico e sob medicação - condições freqüentemente encontradas na população idosa.

Já no sentido inverso, tem-se o efeito do desequilíbrio da saúde bucal sobre a saúde geral do indivíduo, com implicações às vezes dramáticas na qualidade de vida e no bem-estar do idoso. O impacto funcional, social e psicológico das condições bucais pode ser medido por diversas escalas validadas internacionalmente, como o Oral Health Impact Profile (OHIP) (Locker \& Slade, 1993). Condições orais precárias têm um impacto negativo na vida diária de grande parte da população idosa, principalmente em pacientes edentados e pacientes dentados que não têm atendimento odontológico regular, sendo que as principais queixas referem-se a limitações funcionais (di- ficuldade de mastigação, fonação, respiração, aparência, retenção de alimentos nos dentes e próteses e desadaptação de próteses) (Locker \& Slade, 1993).

Além das influências negativas das condições bucais, um estudo longitudinal realizado na Carolina do Norte, Estados Unidos, com mais de mil idosos, demonstrou que os dentes também podem ter influências positivas, como a aparência e a capacidade de se alimentar com satisfação (Strauss \& Hunt, 1993).

Em relação à parte clínica, a maioria das doenças sistêmicas apresenta manifestações bucais que predispõem ao desenvolvimento de processos patológicos, tornando o equilíbrio saúde-doença muito mais frágil. É o que ocorre no caso de diabetes mellitus - que provoca alteração na microvascularização das gengivas e mucosas mesmo em pacientes compensados e da osteoporose, que provoca alterações de densidade óssea também na maxila e na mandíbula. Entretanto, não há evidências científicas de que esses problemas sistêmicos sejam causa direta de problemas bucais, como doenças periodontais (Kamen, 1997).

O maior problema de ordem geral que afeta diretamente as condições de saúde bucal são as doenças incapacitantes, como os distúrbios cognitivos e motores que estão relacionados com má higiene oral. Dessa forma, pacientes portadores de doença de Parkinson avançada, artrite deformante nas mãos, demência, hemiplegia etc., necessitam de ação coordenada da equipe odontológica com familiares/cuidadores, equipe médica e de enfermagem, psicólogos, fisioterapeutas e terapeutas ocupacionais, para manter uma boa higiene bucal e a maior independência possível. Na maioria das vezes, é necessária a reorientação de procedimentos de higiene bucal considerando-se as limitações do indivíduo: adaptação de cabos de escovas, instrumentos para facilitar a passagem de fio dental, uso de substâncias preventivas e terapêuticas (principalmente fluoretos e clorexidina).

A manutenção precária da saúde bucal pode levar a complicações catastróficas. Há indícios de que doenças bucais não tratadas podem levar a infecções sistêmicas (Slavkin, 1999), entretanto ainda são desconhecidas quais as condições bucais específicas ou o grau de severidade que seriam responsáveis pelas complicações de ordem geral (Hollister \& Weintraub, 1993). De todo modo, em caso de qualquer complicação sistêmica no idoso, é fundamental que haja ação interdisciplinar para a resolução tanto do quadro geral, quanto do odontológico. Pacientes em condições de risco por imunodepressão (a serem submetidos a radiotera- 
pia, transplante de órgãos ou com doenças cardíacas) requerem controle/erradicação de focos infecciosos bucais previamente ao tratamento médico.

Alguns autores relatam que uma das mais freqüentes complicações de saúde em pacientes internados em instituições de longa permanência é a pneumonia por aspiração e bacteriemias causadas por microorganismos gramnegativos deslocados de dentes com comprometimento de cáries extensas e periodontopatias severas (Hollister \& Weintraub, 1993; Iacopino, 1997). Pacientes edêntulos também podem desenvolver bacteriemias em virtude de úlceras provocadas por próteses totais malajustadas (Dajani et al., 1997). Algumas bacteriemias transitórias provocadas por infecções bucais podem levar a quadros de endocardite, principalmente em pacientes com defeitos cardíacos estruturais. Nos pacientes de médio e alto risco para essas complicações, realiza-se a cobertura antibiótica profilática antes de procedimentos odontológicos cirúrgicos, de acordo com as recomendações da American Heart Association (Dajani et al., 1997). Em geral, utiliza-se também como medida profilática de ordem local o uso de bochechos de substância antimicrobiana (clorexidina a $0,12 \%$ ).

Além das doenças de ordem sistêmica, também os medicamentos usados pelos idosos têm impacto sobre o ambiente bucal. Em uma ampla revisão sobre o assunto, Paunovich et al. (1997) relataram que a maioria das drogas prescritas mais freqüentemente têm potencial de efeitos colaterais na boca. As reações mais comuns são xerostomia, alterações no paladar e estomatites. Também pode ocorrer hiperplasia gengival decorrente de efeito colateral de anticonvulsivantes. Além disso, muitos medicamentos interferem direta ou indiretamente com os procedimentos odontológicos, devido a interações medicamentosas, tendência a produzir hipotensão postural e alterações de humor.

A xerostomia (sensação de boca seca) é uma queixa bastante comum, presente em cerca de $40 \%$ dos idosos (Sreebny, 1996), provocando distúrbios na fala, mastigação e deglutição, bem como dores bucais. Além da etiologia medicamentosa, a xerostomia pode ocorrer em virtude de desidratação, destruição das glândulas salivares por radioterapia e doenças sistêmicas. Seu tratamento geralmente é paliativo, acompanhado de medidas mais agressivas para a prevenção e o controle das complicações locais, como cáries, ulcerações e infecções nas mucosas (Fox., 1997). Uma complicação geral importante em idosos é resultado da alteração do paladar provocada pela xerostomia, que po- de alterar a dieta e influir no estado nutricional do indivíduo (Paunovich et al., 1997).

A dieta pode afetar a cavidade bucal de várias maneiras direta ou indiretamente. Os dentes são afetados por cáries e doença periodontal, que podem levar à perda dental, a qual, por sua vez, pode influir na escolha da dieta.

Em relação à cárie dental, doença que afeta 95\% da populaçao idosa (Ettinger, 1997), a dieta representa um dos fatores etiológicos mais importantes a ser considerado no aspecto preventivo. Assim, a restrição do consumo excessivo de carboidratos fermentáveis e a redução da freqüência de ingestão destes são medidas recomendadas para prevenir a acidificação bucal por longos períodos em pacientes de alto risco à cárie dental (Johansson \& Birkhed, 1995). No entanto, de modo geral, os hábitos alimentares são difíceis de ser alterados, principalmente no idoso (Papas \& Ettinger, 1998).

Também a mucosa bucal é afetada pela dieta. A ingestão de vitamina A e o consumo freqüente de frutas e vegetais contendo beta-caroteno e outros carotenóides parecem reduzir o risco de câncer bucal (INCA, 1996/1999; Salisbury, 1997). Por exemplo, o desenvolvimento de leucoplasias, lesões precursoras do câncer bucal, está associado ao uso de tabaco e de álcool, bem como à sífilis e às hipovitaminoses, por deficiência de vitamina A e de antioxidantes, como as vitaminas $\mathrm{C}$ e $\mathrm{E}$.

As escolhas dietéticas são influenciadas por fatores mecânicos, psicológicos e sociais (Papas \& Ettinger, 1998). Um estudo amplo realizado no Canadá constatou que cerca de $30 \%$ dos idosos entrevistados tinham que evitar algum tipo de comida devido às condições bucais insatisfatórias (Locker \& Slade, 1993). A perda dos dentes ou uma dentição comprometida, dores bucais e perda do paladar podem forçar muitos pacientes idosos a alterar seus hábitos alimentares. Assim, a escolha dos alimentos e a qualidade nutricional da dieta pode ser afetada pela instalação de próteses parciais removíveis ou próteses totais, principalmente quando mal-adaptadas ou com dentes artificiais gastos (Papas et al., 1998). Daí a importância da manutenção da dentição natural ou de parte dela sempre que possível, assim como a correta informação sobre a adaptação nutricional necessária quando o paciente é portador de próteses.

Analisando dados obtidos de questionários respondidos por 49.501 profissionais de saúde do sexo masculino, de 40 a 80 anos, Joshipura et al. (1996) observaram que indivíduos edentados consumiam menos vegetais, menos fibras e caroteno, e mais colesterol, gordura sa- 
turada e calorias, em comparação com indivíduos com 25 dentes ou mais. Também a análise longitudinal por quatro anos sugeriu que a perda de dentes pode levar a alterações prejudiciais na dieta.

A ação interdisciplinar é indispensável para a resolução de tais desequilíbrios nutricionais. A intervenção do dentista para sanar problemas orais (eliminação de dores e focos infecciosos, restauração da oclusão e reabilitação oral, ajuste de próteses mal-adaptadas) possibilita o retorno das funções de mastigação e deglutição. Já o nutricionista pode orientar uma dieta mais adequada às condições gerais e bucais dos pacientes, com modificações no tipo de alimentos, na apresentação e na consistência da comida. Dessa forma, a associação da restauração da saúde bucal com uma dieta equilibrada e atraente pode devolver ao idoso o prazer de comer. Esse aspecto psicológico não deve ser subestimado, pois a satisfação de poder comer bem é altamente valorizada pelo idoso (Strauss \& Hunt, 1993) e tem implicações na sua auto-estima e no convívio social.

Além da insatisfação com a alimentação, problemas psicológicos têm sido relatados devido à saúde bucal precária, tais como depressão por ausência de elementos dentais (reflexos na auto-imagem e na auto-estima), sintomas de desadaptação, com prejuízos nos relacionamentos social, familiar, amoroso e profissional (Wolf, 1998), e até o isolamento. Em razão de problemas de saúde bucal, cerca de $11 \%$ a $14 \%$ dos idosos relatam que evitam sorrir e dar risadas (Locker \& Slade, 1993; Strauss \& Hunt, 1993).

Seger (1998) salienta que a perda dos dentes é um evento precipitador do sentimento de ser velho, o qual ocorre abruptamente em contraposição ao processo gradual de envelhecimento. Assim, o edentulismo é particularmente associado aos aspectos negativos da velhice, com a não-aceitação social através de perda de empregos (Ferreira, 1997) e de parceiros (Wolf, 1998). Em uma pesquisa com adultos brasileiros de classe média, Wolf (1998:315) verificou que a perda dos dentes é "sentida como prejudicial à organização egóica e fator desencadeante de sentimentos de desamparo, impotência e diminuição da auto-estima". Portanto, a busca de recursos odontológicos para a substituição dos dentes perdidos estaria diretamente relacionada com a demanda de reconstituição da imagem pessoal e social dos indivíduos.

Por outro lado, a valorização do autocuidado, com a higiene pessoal, incluindo a higiene bucal, somente ocorre quando o indivíduo está bem consigo mesmo e mantém sua auto-ima- gem como um aspecto importante de vida. A auto-estima é importante para que ocorra mudança de hábitos no processo de promoção de saúde. O abandono de hábitos nocivos, como o tabagismo e o alcoolismo, e a adoção de hábitos saudáveis dependem muito mais da valorização de si mesmo pelo indivíduo do que de esforços profissionais.

A auto-estima também é peça fundamental na procura e utilização dos serviços de saúde, incluindo os cuidados odontológicos. Segundo Seger (1998), os idosos podem reagir à perda dos dentes de forma inconformista ou conformista. Os inconformistas procuram rapidamente os cuidados profissionais e são mais dedicados ao tratamento; já os conformistas assumem uma atitude passiva diante de tratamentos e aceitam as perdas como naturais. As atitudes dos idosos conformistas e de seus cuidadores deve ser mudada para que a demora de tratamento não traga mais prejuízos para sua saúde. Nesse caso, mesmo que recursos de assistência estejam disponíveis, a precária situação bucal dos idosos não será melhorada se não houver orientação pela equipe de saúde.

Todos esses aspectos de inter-relação entre a saúde bucal e a saúde geral podem e devem ser detectados por qualquer membro da equipe interdisciplinar. O ponto fundamental é saber para poder enxergar, o que evidencia o conhecimento como requisito básico para a atenção interdisciplinar ao idoso.

\section{Considerações finais}

Neste trabalho, procurou-se expor a indissociabilidade dos aspectos de saúde bucal e de saúde geral no atendimento ao idoso, ressaltando a importância do conhecimento através da troca de informações. Esse aspecto é fundamental em todos os níveis de atendimento, seja na promoção de saúde, na prevenção específica ou na reabilitação, e envolve não apenas a equipe de profissionais, mas também os idosos e seus familiares, as autoridades e a comunidade. Assim, a informação possibilita o encontro das diversas atuações profissionais por meio de ações integradas mais objetivas e eficazes, que respeitem as necessidades reais do idoso. Nesse contexto, a odontologia também se torna parte do time, à medida que é percebida como necessária.

Especificamente na área odontológica, alguns problemas podem ser detectados e devem ser sanados rapidamente. Um deles é a necessidade urgente de formação de recursos humanos capacitados em odontologia geriátri- 
ca para o atendimento especializado ao idoso, principalmente aos indivíduos com incapacidades. Além disso, tanto na graduação, quanto nos cursos avançados, a odontologia deve incorporar uma nova mentalidade de formação, com base na interdisciplinaridade e na atenção integral à saúde. Outro problema é a inexistência de programas preventivos e de assistência odontológica direcionados à terceira idade em nível coletivo. Também na odontologia a prevenção é a chave para a atenção ao idoso, com reflexos visíveis na análise de custo-benefício: os gastos são menores e o acesso é mais amplo.
Retoma-se, por fim, o pensamento exposto na introdução, segundo o qual a odontologia deve obter na geriatria e na gerontologia as bases para uma visão geral do idoso e do envelhecer. À primeira vista, parece haver, aqui, um paradoxo ao se considerar que não há um idoso único, mas sim que cada idoso é único e que, portanto, não haveria a possibilidade de uma visão generalizada. Contudo, essa posição não se torna contraditória quando se busca no conhecimento interdisciplinar o entendimento do idoso e do processo de envelhecimento para poder, cada vez mais, enxergar a singularidade em cada um.

\section{Referências}

ALBUQUERQUE, A. J., 1982. O espectro da odontologia geriátrica: Ensino. Revista Gaúcha de Odontologia, 30:276-277.

CURY, J. A., 1999. Controle químico da placa dental. In: ABOPREV: Promoção de Saúde Bucal (L. Krieger, org.), pp. 129-140, São Paulo: Editora Artes Médicas.

DAJANI, A. S.; TAUBERT, K. A.; WILSON, W.; BOLGER, A. F.; BAYER, A.; FERRIERI, P.; GEWITZ, M. H.; SHULMAN, S. T.; NOURI, S.; NEWBURGER, J. W.; HUTTO, C.; PALLASCH, T. J.; GAGE, T. W.; LEVISON, M. E.; PETER, G. \& ZUCCARO Jr., G., 1997. Prevention of bacterial endocarditis: Recommendations by the American Heart Association. Journal of the American Dental Association, 128:11421151.

DEL BEL CURY, A. A.; REBELO, M. A. B. \& CURY, J. A., 1994. Efeito de bochecho com clorexidina $(\mathrm{CH}) \mathrm{e}$ flúor (F) na redução de formação de placa dental e incorporação de flúor no esmalte dental. $R e$ vista Brasileira de Odontologia, 51:26-29.

DINI, E. L. \& CASTELLANOS, R. A., 1993. Doenças periodontais em idosos: Prevalência e prevenção para populações de terceira idade. Revista Brasileira de Odontologia, 50:3-9.

ERICKSON, L., 1997. Oral health promotion and prevention for older adults. Dental Clinics of North America, 41:727-750.

ETTINGER, R. L., 1997. The unique oral health needs of an aging population. Dental Clinics of North America, 41:633-649.

FDI (Fédération Dentaire Internacionale), 1993. Necesidades de salud bucal del anciano. FDI Dental World, 2:13-15

FERREIRA, R. A., 1997. Odontologia: Essencial para a qualidade de vida. Revista da Associação Paulista de Cirurgiões-Dentistas, 51:514-521.
FOX, P. C., 1997. Management of dry mouth. Dental Clinics of North America, 41:863-875.

FRARE, S. M.; LIMAS, P. A.; ALBARELLO, F. J.; PEDOT, G. \& RÉGIO, R. A. S., 1997. Terceira idade: Quais os problemas bucais existentes? Revista da Associação Paulista de Cirurgiões-Dentistas, 51:573576.

HOLLISTER, M. C. \& WEINTRAUB, J. A., 1993. The association of oral status with systemic health, quality of life, and economic productivity. Journal of Dental Education, 57:901-912.

HOLM-PEDERSEN, P. \& LÖE, H., 1996. Textbook of Geriatric Dentistry. Copenhagen: Munksgaard.

IACOPINO, A. M., 1997. Understanding and treating aging patients. Quintessence International, 28: 622-626.

INCA (Instituto Nacional do Câncer), 1996/1999. Câncer de Boca. Manual de Detecção de Lesões Suspeitas. 7 maio $1999<$ http:// www.inca.org.br/ manual/boca/index.html>.

JACOB FILHO, W. \& SITTA, M., 1996. Interprofissionalidade. In: Gerontologia (M. Papaléo Neto, org.), pp. 440-450, São Paulo: Editora Atheneu.

JITOMIRSKI, F. \& JITOMIRSKI, S., 1987. Odontogeriatria: A odontologia do futuro. Dens - Fase II, 2:5-9.

JOHANSSON, I. \& BIRKHED, D., 1995. A dieta e o processo cariogênico. In: Cariologia Clínica (A. Thylstrup \& O. Fejerskov, org.), pp. 283-310, São Paulo: Livraria Santos Editora.

JOSHIPURA, K. J.; WILLET, W. C. \& DOUGLAS, C. W., 1996. The impact of edentulousness on food and nutrient intake. Journal of the American Dental Association, 127:459-467.

KAMEN, P. R., 1997. Periodontal care. Dental Clinics of North America, 41:751-762.

KINA, S.; CONRADO, C. A.; BRENNER, A. J. \& KURIHARA, E., 1996. O ensino da estomatogeriatria no 
Brasil: A experiência de Maringá. Revista de Odontologia da Universidade de São Paulo, 10:69-73.

KÜNZEL, W., 1991. Conceptual demands of oral health care for the elderly. In: Geriatric Dentistry in Eastern European Countries (W. Künzel, ed.), pp. 1133, Chicago: Quintessence.

LOCKER, D. \& SLADE, G., 1993. Oral health and the quality of life among older adults: The oral health impact profile. Journal of the Canadian Dental Association, 59:830-838.

MADEIRA, A. A.; CAETANO, M. \& MINATTI, E. J., 1987. Odontogeriatria: Uma necessidade curricular. Revista Brasileira de Odontologia, 44:6-12.

MS (Ministério da Saúde), 1993. Relatório Final da Segunda Conferência Nacional de Saúde Bucal. Brasília: Conselho Nacional de Saúde, Ministério da Saúde.

NARVAI, P. C., 1999. Diagnóstico de saúde bucal. In: Odontologia em Saúde Coletiva. Manual do Aluno (Departamento de Odontologia Social, org.), pp. 3-12, São Paulo: Faculdade de Odontologia, Universidade de São Paulo.

NIESSEN, L. C. \& GIBSON, G., 1997. Oral health for a lifetime: Preventive strategies for the older adult. Quintessence International, 28:626-630.

PAPAS, A. S. \& ETTINGER, R. L., 1998. Symposium overview: The inter-relationship of diet and oral health. Special Care in Dentistry, 18:5.

PAPAS, A. S.; PALMER, C. A.; ROUNDS, M. C. \& RUSSELL, R. M., 1998. The effects of denture status on nutrition. Special Care in Dentistry, 18:17-25.

PAUNOVICH, E. D.; SADOWSKY, J. M. \& CARTER, P., 1997. The most frequently prescribed medications in the elderly and their impact on dental treatment. Dental Clinics of North America, 41: 699-726.

PUCCA Jr., G. A., 1996. Saúde bucal do idoso: Aspectos socais e preventivos. In: Gerontologia (M. Papaléo Neto, org.), pp. 297-310, São Paulo: Editora Atheneu.

PUCCA Jr., G. A., 1998. Perfil do Edentulismo e do Uso de Prótese Dentária em Idosos Residentes no Município de São Paulo. Dissertação de Mestrado, São Paulo: Escola Paulista de Medicina, Universidade Federal de São Paulo.
REYNOLDS, M. W., 1997. Education for geriatric oral health promotion. Special Care in Dentistry, 17: 33-36.

ROISINBLIT, R., 1996. La atención odontológica del anciano. Revista de la Asociación Odontológica Argentina, 84:94-98.

ROSA, A. G. F.; FERNANDEZ, R. A. C.; PINTO, V. G. \& RAMOS, L. R., 1992. Condições de saúde bucal em pessoas de 60 anos ou mais no Município de São Paulo (Brasil). Revista de Saúde Pública, 26:155160.

RUTKAUSKAS, J. S., 1997. The Dental Clinics of North America. Clinical Decision-Making in Geriatric Dentistry. Philadelphia: W. B. Saunders Company.

SALISBURY, P. L., 1997. Diagnosis and patient management of oral cancer. Dental Clinics of North America, 41:891-914.

SAUNDERS, M. J., 1996. The roles of the dentist and the dental hygienist on interdisciplinary teams providing health care for elderly patients. In: Textbook of Geriatric Dentistry (P. Holm-Pedersen \& H. Löe, eds.), pp. 560-575, Copenhagen: Munksgaard.

SEGER, L., 1998. Psicologia aplicada à prótese. In: Psicologia e Odontologia: Uma Abordagem Integradora (L. Seger, org.), pp. 275-286, São Paulo: Livraria Santos Editora.

SLAVKIN, H. C., 1999. Does the mouth put the heart at risk? Journal of the American Dental Association, 130:109-113.

SREEBNY, L. M., 1996. Xerostomia: Diagnosis, management and clinical complications. In: Saliva and Oral Health (W. M. Edgar \& D. M. O'Mullane, eds.), pp. 43-66, London: British Dental Association.

STRAUSS, R. P. \& HUNT, R. J., 1993. Understanding the value of teeth to older adults: Influences on the quality of life. Journal of the American Dental Association, 124:105-110.

WERNER, C. W.; SAUNDERS, M. J.; PAUNOVICH, E. \& YEH, C., 1998. Odontologia geriátrica. Revista da Faculdade de Odontologia de Lins, 11:62-70.

WOLF, S. M. R., 1998. O significado psicológico da perda dos dentes em sujeitos adultos. Revista da Associação Paulista de Cirurgiões-Dentistas, 52: 307-316. 